\title{
LEGAL OPINION
}

\section{On being an expert witness in sexual and reproductive health}

\author{
Sam Rowlands ${ }^{1,2}$ \\ ${ }^{1}$ Clinical Lead, Contraception and Sexual Health, Dorset HealthCare, Bournemouth, UK \\ ${ }^{2}$ Visiting Professor, Faculty of Health and Social Sciences, Bournemouth University, Bournemouth, UK
}

\section{Correspondence to:}

Dr Sam Rowlands, Faculty of Health and Social Sciences, Bournemouth University, R506 Royal London House, Christchurch Road, Bournemouth BH1 3LT, UK; srowlands@bournemouth.ac.uk

Keywords: law, expert witness, medicolegal, sexual and reproductive health

Word count: 1,583 words

\begin{abstract}
A new generation of expert witnesses in sexual and reproductive health is needed, including those in nursing as well as medical roles. Being an expert witness is a significant commitment alongside clinical work. Nevertheless, the work is stimulating and rewarding. Training is essential before starting medicolegal work. In particular expert witnesses need to be able to apply appropriate legal tests to the evidence, to deal with the range of expert opinion on a matter and explain clearly what constitutes an appropriate standard of care for a clinician in their discipline and specialty. Expert witnesses must be aware of pitfalls such as being sued for substandard work and being reported to their professional regulator for straying outside their area of expertise. Expert witnesses must be truly independent and ideally their reports should be the same whoever they receive their instructions from. In addition to report writing, expert witnesses are required to comment on court documents, participate in conferences with a barrister and hold formal discussions with an opposing expert witness. Expert witnesses need to be adminstratively efficient and responsive. Although appearance in court is not that common, this is an essential part of the role. Apart from litigation in the civil courts, other types of case may present themselves including patent cases, work in the Court of Protection and health professionals' Fitness to Practise hearings.
\end{abstract}




\section{Key message points}

Working as an expert witness provides intellectual stimulation and contributes to the delivery of justice

Medicolegal training is essential for the role as legal concepts are mostly alien to medical science

The main task of expert witnesses in sexual and reproductive health is to provide opinion evidence in the civil courts in relation to litigation

\section{Introduction}

During the 20 years I have worked as an expert witness it has become clear to me that there are many misconceptions regarding this important role. Doubts about the wisdom of retired clinicians giving their opinion in a contemporary case ${ }^{1}$ have led some to cease their expert witness work earlier than they might otherwise have done, so reducing the pool of expert witnesses. In addition, case law has now determined that misconduct as an expert witness can result in suspension ${ }^{2}$ or even erasure $^{3}$ from the professional register. Further clarification is needed on how expert witnesses who no longer see patients should revalidate. ${ }^{4}$ There are few sexual and reproductive health (SRH) specialists with the appropriate credentials to be an expert witness; in some cases gynaecologists take on this work even though they are not from this specialty. There is a need to encourage a new generation capable of fulfilling this challenging yet rewarding responsibility.

\section{What is an expert witness?}

It is important to distinguish between an expert and an expert witness (traditionally called skilled witnesses in Scotland). All clinicians who follow training in a specialty become experts in their field; however this alone is not adequate to undertake expert witness work. Expert witnesses have to be 
able to formulate 'opinion evidence' and communicate that 'opinion evidence' to a court of law or other quasi-judicial hearing.

Previously, writing legal reports might have been seen as an activity to fill a vacuum, possibly following retirement from the National Health Service, and to earn some extra cash. However, being an expert witness involves more than just writing reports based on personal expertise; it is an undertaking that should be embarked upon only if a clinician is prepared to make a significant commitment in terms of time and energy. Considerable time can be taken up preparing for and attending meetings with a fellow expert witness or meetings with lawyers. Any case can end up in court and this aspect of the work, although not common, must be seen as part of the role. A court case may take several days, with some time waiting to give evidence.

Motivation to embark on the path to becoming an expert witness should be based on the desire for an intellectual challenge and to be in a position to offer the parties involved in a case the services of a competent, independent expert. The work should not be seen as a 'sideline'. It has to be taken seriously, particularly as there is no longer immunity from being sued in the UK. ${ }^{5}$ One's whole professional reputation can be damaged if the quality of work is found to be inadequate or if one strays outside one's area of expertise. ${ }^{4}$ Nevertheless, much can be learnt from cases worked on and this learning then fed back into one's own clinical practice.

\section{What training is required?}

The Medical Defence Union advises that a clinician should have accrued $10-15$ years of specialist experience before working as an expert witness. ${ }^{6}$ In the past, some clinicians would launch into medicolegal work with little or no preparation. This is highly inadvisable in the modern climate. There are a number of introductory courses to choose from and more advanced courses to follow to hone one's knowledge, especially knowledge of the English Civil Procedure Rules part $35^{7}$ (Box 1). There are also professional organisations which, in addition to training opportunities, offer newsletters, annual conferences and other activities and resources that are invaluable to the practising expert witness (Box 1). For those who want to take training to an even higher level a Civil Expert Certificate may be gained in association with Cardiff University Law School ${ }^{8}$, or postgraduate diplomas in medical law or even Master's degrees in medical law that are offered by several universities. Much of the necessary work can be done by distance learning.

\section{[Box 1 near here]}


It is imperative that expert witnesses should have had training in the following aspects of their work: ${ }^{8}$

- Applying the civil standard of proof and appropriate legal tests to the evidence

○ these include 'on the balance of probabilities' ('more likely than not'), 'but for the incident the claimant would not have suffered ...' and 'the actions of the doctor fell below the standard reasonably to be expected of an SRH specialist at that time'.

- Dealing with the range of expert opinion on a matter

- expert witnesses must express not only their own opinion but the opinions of colleagues with whom they would disagree.

- Explaining clearly what constitutes an appropriate standard of care

- this will depend on the relevant training, guidelines and textbooks available at the time of the case. Also case law has moved on and merely using the Bolam test ('The standard of a responsible body of medical opinion') is not sufficient.

It is obvious to the legal profession when individuals are not thoroughly familiar with these areas.

Keeping up to date is similar to clinical continuing professional development and equally vital. Regular attendance at courses and reflection on cases, testimonials from clients and peer references are needed for the annual appraisal, in order to cover the whole scope of a clinician's practice.

\section{Working as an expert witness}

The professional membership organisations (Box 1) advise that expert witnesses must register themselves with the Information Commissioner (http://ico.org.uk) and should take out dedicated insurance over and above their professional indemnity cover. To get established it is useful to have one's details on one or more directories or registers; the AvMA (Action against Medical Accidents) database ${ }^{9}$ is particularly relevant in relation to claimant ('pursuer' in Scots law and 'plaintiff' elsewhere) work. Many expert witnesses have websites through which instructing lawyers can look at their experience and credentials and can then make contact by email. Repeat work is more likely to come in for a well-organised, responsive expert witness who writes in a clear, focused, analytical yet succinct way.

Expert witnesses interact on a regular basis with the lawyers who give them instructions. The wise expert witness will want to enter into a firm contractual agreement with instructing solicitors before doing any work. Since the English Jackson reforms ${ }^{10}$ there has been a clampdown on costs and, 
therefore, fees; expert witnesses need to protect themselves from failure to be paid for work that may have taken many hours. It is wise to have robust and comprehensive terms and conditions in place. Templates for terms and conditions, the expert's declaration, the statement of truth, a twopage $\mathrm{CV}$ suitable for a report and much more are available as a member benefit of the professional organisations listed in Box 1.

The mindset of lawyers and the timescales that they work to (much slower than in medicine) take some getting used to. Nevertheless, in recent times the courts have been taking a much more proactive role in case management; cases no longer remain dormant unless there is a good reason for this. Once a court timetable is imposed, the pace of a case can be relatively quick and expert witnesses may be required to produce revised reports without much notice. It is thus important that an expert witness remains contactable and has an efficient office.

All communications must be addressed as if to an 'informed layperson'; ${ }^{11}$ medical terminology should seldom be used and, if it is, needs to be translated into ordinary English. Much of the work will be litigation which requires thinking along the lines of duty of care, breach of duty and causation. ${ }^{12}$ Writing a report ${ }^{11}$ comes early on in a case, but when a case proceeds this can be followed (sometimes several years later) by commenting on court documents, a conference with a barrister, a discussion with the opposing expert witness and ultimately appearance in court. In SRH one often does not need to see the claimant; a report is based on the paperwork, which can be extensive - expert witnesses need adequate space to securely store copious amounts of paper. The majority of cases are settled before going to court, but an expert witness has to be prepared for the eventuality of a court appearance. The expert witness will need to take care to balance work for both claimant and defendant so as to be seen to be truly independent - and in an ideal world their reports should be identical, whichever side they are instructed by.

Apart from litigation in the civil courts there are other areas of legal work which may crop up, albeit less often. These include patent cases, work in the Court of Protection ${ }^{13}$ (www.gov.uk/courtstribunals/court-of-protection) and Fitness to Practise hearings of the General Medical Council or Nursing and Midwifery Council. These non-litigation cases are less adversarial but nevertheless just as intellectually stimulating. Clinicians who are sexologists or forensic physicians may work on cases in the criminal courts.

\section{Expanding roles}


Sexual and reproductive health is not a high volume or high quantum (amount of damages) area like orthopaedics or obstetrics. The commonest cases are litigation around contraceptive devices. Examples of types of case are drug interactions, non-insertion and nerve injury in the case of subdermal implants and uterine perforation in the case of IUDs. Delay in the diagnosis of pregnancy following contraceptive failure is also a perennial subject.

Traditionally expert witnesses in medical cases were invariably doctors. As the role of other members of the multidisciplinary team has expanded there is a need for expert witnesses from other disciplines, particularly nurses. A case involving a clinician should have an expert appointed in the same discipline and specialty in order that the standard of care can be properly assessed.

I can recommend working as an expert witness as a challenging yet rewarding activity. I would be happy to be contacted by members of SRH specialist teams who are contemplating working as expert witnesses at info@samrowlands.net.

BOX

\section{Box 1 Useful resources}

Organisations that offer training

AvMA www.avma.org.uk

Bond Solon www.bondsolon.com

Professional Solutions www.prosols.uk.com

Professional membership organisations

Academy of Experts www.academyofexperts.org

Expert Witness Institute www.ewi.org.uk

\section{References}

(1) Henderson v R [2010] EWCA Crim 1269 at paras 207 and 208. 2010.

(2) Pool v GMC [2014] EWHC 3791 (Admin). 2014.

(3) Squier v GMC [2015] EWHC 299 (Admin). 2015.

(4) Information for doctors who don't have a designated body http://www.gmcuk.org/doctors/revalidation/25045.asp (Accessed 7 November 2015). Manchester: General Medical Council; 2015.

(5) Jones v Kaney [2011] UKSC 13. 2011. 
(6) Acting as a medical expert witness http://www.themdu.com/guidance-andadvice/guides/consultant-pack/acting-as-an-expert-witness (Accessed 31 October 2015). Consultant guide. London: MDU; 2015. 33-34.

(7) Civil Procedure Rules Part 35: Experts and assessors https://www.justice.gov.uk/courts/procedure-rules/civil/rules/part35 (Accessed 27 October 2015). London: Ministry of Justice; 2015.

(8) Bond Solon. Expert witness qualifications http://www.bondsolon.com/expertwitness/qualifications.aspx (Accessed 27 October 2015). London: Bond Solon; 2015.

(9) AvMA. Medical experts http://www.avma.org.uk/resources-for-professionals/informationfor-medical-experts/ (Accessed 27 October 2015). London: Action Against Medical Accidents; 2015.

(10) Taddia M. Jackson reforms: shock therapy http://www.lawgazette.co.uk/practice/jacksonreforms-shock-therapy/5040610.fullarticle (Accessed 27 October 2015). London: The Law Society Gazette; 2014.

(11) Eyre G, Alexander L. Writing medico-legal reports in civil claims: an essential guide. 2 nd ed. London: Professional Solutions Publications; 2015.

(12) Herring J. Medical law and ethics. 5th ed. Oxford: Oxford University Press; 2014.

(13) Rowlands S. Learning disability and contraceptive decision making. J Fam Plann Reprod Health Care 2011; 37:173-178. 